\title{
PELAKSANAAN PASAL 27 UNDANG-UNDANG NO. 23 TAHUN 2011 \\ MENGENAI ZAKAT PRODUKTIF DI BAZNAS KABUPATEN \\ KARANGANYAR
}

\author{
Agus Rianto, Junaidi, Ary Setyawan \\ Fakultas Hukum Universitas Sebelas Maret \\ Email:agusrianto8@gmail.com, junaidi_fhuns@yahoo.com, \\ cenase@yahoo.com
}

\begin{abstract}
The existence of zakat organizer institution, either National Amil Zakat Board (BAZNAS) or Amil Zakat Institutions (LAZ) is one of the efforts in managing zakat in Indonesia. In addition, the government gives positive response by creating the Law 23 of 2011 about Zakat Managing. The example of new thought about zakat is that there is productive zakat that has not been known before. This research concern how productive zakat managing implemented by $B A Z N A S$ of Karanganyar Regency. Then, this research saw what problems that faced by BAZNAS of Karanganyar Regency in managing productive zakat.This research was empiric research using interactive method. This research took place in BAZNAS of Karanganyar Regency. The result of this research is a model in managing productive zakat that is more beneficial in society empowerment to solve poverty and scientific publication.
\end{abstract}

Keyword: Productive zakat, BAZNAS, society empowerment

\section{Abstrak}

Keberadaan lembaga-lembaga pengelola zakat, baik Badan Amil Zakat Nasional (BAZNAS) maupun Lembaga Amil Zakat (LAZ) merupakan salah satu bukti hasil ijtihad terkait dengan zakat di Indonesia. Selain itu respon positif pemerintah terhadap zakat ialah dengan dikeluarkannya Undang-Undang Nomor 23 Tahun 2011 Tentang Pengelolaan Zakat. Pemikiran baru dalam bidang zakat diantaranya adalah munculnya jenis zakat produktif yang dulu tidak dikenal. Penelitian ini melihat bagaimana pengelolaan zakat produktif yang dilaksanakan oleh BAZNAS Kabupaten Karanganyar dan berbagai kendala apa saja yang dialami BAZNAS Kabupaten Karanganyar selama mengelola zakat produktif. Jenis penelitian ini adalah penelitian empiris dengan metode analisis model interaktif. Lokasi penelitian di BAZNAS Kabupaten Karanganyar. Hasil penelitian ini adalah model dalam pengelolaan zakat produktif yang lebih berdaya guna dalam pemberdayaan masyarakat dalam mengatasi kemiskinan dan publikasi ilmiah.

Kata kunci: Zakat Produktif, BAZNAS, Pemberdayaan Masyarakat. 


\section{A. Pendahuluan}

Dalam sejarah kerasulan Muhammad SAW, tercatat bahwa kehadiran beliau ditengah masyarakat Arab adalah untuk menyerukan kalimat tauhid dan menegakkan keadilan yang merupakan inti dari ajaran Islam, termasuk di dalamnya adalah keadilan sosial ekonomi (Haq, 1967:23-25). Tidak dapat disangkal bahwa ayat-ayat pertama (makiyyah) mengandung panggilan untuk beriman kepada Allah (tauhid) dan menentang tatanan yang timpang saat itu, khususnya dalam masalah disequilibrium ekonomi yang mana pada saat itu akses dalam bidang ekonomi dikuasai sekelompok kecil elit (bangsawan) Masyarakat Arab.

Kemiskinan merupakan bahaya besar bagi umat manusia dan tidak sedikit umat yang jatuh peradabannya karena kefakiran, sebagaimana sabda Nabi Muhammad "kefakiran itu mendekati pada kekufuran".

Zakat merupakan salah satu konsep yang ditawarkan agama untuk menanggulangi kemiskinan karena tujuan zakat tidak sekedar menyantuni orang miskin secara konsumtif tetapi mempunyai tujuan yang lebih permanen yaitu untuk memberdayakan kehidupan seseorang, sehingga bisa menikmati kesejahteraan dan mejauhkannya dari kemiskinan.

Nabi Muhammad SAW pernah memberikan sedekah kepada seorang fakir sebanyak dua dirham sambil memberi anjuran agar mempergunakan uang itu satu dirham untuk makan dan satu dirham lagi untuk membeli kapak dan bekerja dengan kapak itu. Lima belas hari kernudian orang ini datang lagi kepada Nabi SAW dan menyampaikan bahwa ia telah bekerja dan berhasil mendapat sepuluh dirham. Separuh uangnya dipergunakan untuk makan dan separuhnya lagi untuk membeli pakaian. Riwayat tersebut merupakan contoh yang sangat sederhana yang diberikan oleh Rasulullah mengenai bagaimana zakat itu sebaiknya didistribusikan dan didayagunakan, demikian juga memberikan peringatan kepada setiap pengelola zakat bahwa keberhasilan zakat tergantung kepada pendayagunaan dan pemanfaatannya.

Zakat yang selama ini dikaji secara dogmatis-normatif mulai terbuka untuk dikaji secara kontekstual. Ide-ide pelaksanaan dan pengelolaan zakat 
yang masih bersifat tradisional mulai dirubah polanya sesuai dengan kondisi kehidupan nyata masyarakat modern sekarang ini. Zakat yang selama ini hanya bersifat karitas, belas kasihan dari si kaya kepada si miskin yang bersifat atas bawah (top down) yang menempatkan orang kaya sebagai subyek dan orang miskin sebagai obyek (Mangunwijaya, 1997:55-59) sudah saatnya untuk dikelola sesuai dengan pola dan perkembangan manajemen modern agar lebih berdayaguna bagi pemberdayaan kelompok-kelompok rentan dalam masyarakat. Pemikiran dan ide yang bersifat reformatif perlu dikedepankan. Pintu-pintu ijtihad dalam bidang zakat harus dibuka kembali (Abdullah, 2000:29), demi mencapai substansi dari ajaran zakat yaitu memberdayakan orang miskin dan mengurangi jurang pemisah yang terlalu dalam antara si kaya dan si miskin.

Ijtihad dalam bidang zakat telah dan selalu dilaksanakan di Indonesia, baik secara individual maupun konstitusi. Dalam hal ini salah satu adalah dibuatnya jenis zakat produktif yang bisa diberikan dalam bentuk modal usaha untuk masyarakat Muslim yang tidak punya yang bisa dimanfaatkan sebagai modal usaha untuk mencari nafkah.

Keberadaan Badan Amil Zakat Nasional (BAZNAS) serta berbagai Lembaga Amil Zakat (LAZ) merupakan salah satu bukti dari proses ijtihad tersebut dan merupakan respon positif pemerintah terhadap pelaksanaan zakat di Indonesia. Selain itu respon positif pemerintah terhadap zakat ialah dengan dikeluarkannya peraturan tentang zakat yaitu Undang-Undang Nomor 38 Tahun 1999 tentang Pendayagunaan zakat yang sekarang telah disempurnakan dengan Undang-Undang Nomor 23 Tahun 2011 Tentang Pengelolaan Zakat.

Aktualisasi Undang-Undang Zakat itu merupakan tugas daerah masing-masing untuk menginventarisir, mengumpulkan dana dari masyarakat dan mengelolanya sesuai dengan ketentuan nash. Tugas ini merupakan bagian dari aktualisasi makna zakat yang substansial yaitu memberikan dana yang memberdayakan, mengusahakan kelompok penerima zakat keluar dari 
lingkaran kemiskinan atau dalam kata lain yaitu menjadikan si penerima zakat menjadi si pembayar zakat.

Berdasarkan uraian latar belakang di atas, maka permasalahan yang akan diteliti adalah sebagai berikut:

1. Bagaimanakah BAZNAS Kabupaten Karanganyar mengelola zakat produktif mulai dari penghimpunan sampai dengan penyalurannya?

2. Apakah kendala yang dihadapi BAZNAS Kabupaten Karanganyar dalam mengelola zakat produktif dan bagaimana solusinya?

\section{B. Metode Penelitian}

Jenis penelitian yang digunakan adalah penelitian empiris (empirical research).Penelitian dilakukan dengan menggunakan pendekatan perundangundangan (statute approach), yaitu yaitu pendekatan dengan menjadikan norma atau kaidah hukum tertentu sebagai dasar kajian dalam mengupas setiap permasalahan yang diangkat (Peter Mahmud Marzuki, 2007: 37).Selanjutnya berbagai norma atau kaidah hukum tersebut dijadikan sebagai dasar acuan untuk melakukan pengujian apakah realita yang berlangsung dilapangan telah sesuai atau belum dengan aturan sebagaimana yang telah digariskan dalam norma hukum tersebut.Sehingga karenanya, penelitian ini bersifat empiris deskriptif analitis, yaitu menggambarkan berbagai masalah hukum dan fakta-fakta yang ada (Soerjono Soekanto, et.al., 2007: 56). Lokasi penelitian ini di wilayah Kabupaten Karanganyar dengan objek penelitian lembaga pengelola zakat yang dalam hal ini adalah BAZNAS Kabupaten Karanganyar. Pengumpulan bahan hukum dilakukan melalui studi pustaka berupa peraturan perundang-undangan, literatur buku dan 
lain sebagainya. Disamping itu juga dengan melakukan penelitian lapangan untuk mendapatkan data secara langsung di lapangan melalui wawancara.

\section{Hasil Penelitian dan Pembahasan}

1. Pengelolaan zakat produktif di BAZNAS Kabupaten Karanganyar mulai dari penghimpunan sampai dengan penyalurannya.

Berdasarkan analisis Peneliti, kesadaran masyarakat Karanganyar dalam menunaikan kewajiban zakat, anjuran infak dan shadaqah sudah cukup tinggi, sehingga bisa terkumpul dana zakat, infak dan shadaqah tiap bulannya rata-rata sebesar Rp. 70 juta. Bila dilhat dari besarnya zakat, infak dan shadaqah yang bisa terkumpul sebanyak itu, hal ini menunjukkan kalau dana zakat, infak dan shadaqah dikumpulkan secara teratur dari umat Islam, maka dana tersebut bisa digunakan untuk berbagai kepentingan masyarakat.

Di Karanganyar sendiri ada hal yang cukup menarik dalam menggali dana zakat, infak dan shadaqah. Dalam hal ini tiap PNS diberi formulir kesediaan untuk menunaikan zakat, infak dan shadaqah. Dalam formulir ini diberikan kebebasan pada tiap PNS, apakah mereka bersedia membayar zakat atau infak saja atau hanya shadaqah saja, atau bahkan mau membayar ketiga-tiganya.

Salah satu hal yang menarik untuk membantu masyarakat yang kurang mampu dari segi ekonomi adalah bantuan modal usaha berupa kambing dan beberapa bentuk bantuan modal lainnya. Sebagai contoh beberapa hal yang sudah dilakukan BAZIS Karanganyar, sebelum berganti istilah menjadi BAZNAS Karanganyar adalah: (Abdul Muid, Nur Arifin dan Moh. Azis Marnawi, 2001 : 16) :

1. Memberi bantuan modal usaha berupa 25 ekor kambing pada tahun 1994 untuk Desa Bolon, Kecamatan Colomadu dan telah berkembang menjadi sekitar 75 ekor.

2. Bantuan 15 ekor kambing untuk daerah Puntukrejo, Kecamatan Ngargoyoso pada tahun 1994. Selanjutnya bisa berkembang 
menjadi sekitar 30 ekor dan digulirkan lagi pada 88 kepala keluarga yang lain.

3. Bantuan 25 ekor kambing untuk Desa Kemiri, Kecamatan Kebakkramat pada tahun 1994 untuk 25 kepala keluarga. Selanjutnya bisa berkembang menjadi sekitar 44 ekor kambing.

4. Bantuan untuk Desa Kaliwuluh, Kecamatan Kebakkramat berupa 15 ekor kambing yang kemudian digulirkan pada beberapa kepala keluarga yang lain.

5. Bantuan 10 ekor kambing untuk Panti Asuhan Wakaf Triyoso, Ngrawoh, Tegalgede, Karanganyar.

6. Bantuan satu buah mesin obras "Pegazus" untuk kaum penderita cacad di daerah Jongke, Karanganyar.

7. Pada tahun 1994 memberi bantuan mesin obras pada kaum penderita cacad di daerah Kaling, Kecamatan Tasikmadu, Karanganyar.

8. Memberi bantuan 35 buah becak pada 35 orang dan berkembang menjadi 55 buah becak, namun dalam perkembangannya becakbecak itu kemajuannya tidak ada laporan sama sekali ke BAZIS.

9. Memberi bantuan modal untuk 26 kelompok usaha di Desa Karangsari, Kecamatan Gondangrejo masing-masing perkelompok diberi bantuan Rp 100 ribu. Selanjutnya digulirkan lagi pada 20 kelompok usaha baru masing-masing diberi bantuan Rp. 100 ribu rupiah, hanya sayang tak ada laporan perkembangan selanjutnya.

Berdasarkan hal tersebut di atas, menurut Peneliti penunaian zakat, infak dan shadaqah sudah merupakan kewajiban umat Islam yang mampu dan hasil pengumpulan zakat, infak dan shadaqh itu merupakan sumber dana yang potensial untuk mewujudkan kesejahteraan masyarakat luas. Tak dapat disangkal kalau zakat, infak dan shadaqah tersebut merupakan pranata keagamaan yang bisa digunakan untuk mewujudkan keadilan sosial bagi seluruh rakyat Indonesia dengan titik berat mengangkat kehidupan orang tidak mampu. Menurut Peneliti pun dalam masalah 
pendistribusian zakat, infak dan shadaqah ini harus ada pula penyempurnaan sistem pengelolaan zakat, infak dan shadaqah itu agar lebih berhasil guna dan berdaya guna serta dapat dipertanggung jawabkan.

Menurut Peneliti, dengan pengelolaan yang baik dan terukur, zakat, infak dan shadaqah merupakan sumber dana potensial yang dapat dimanfaatkan untuk memajukan kesejahteraan umum bagi seluruh masyarakat supaya dapat dimanfaatkan dengan optimal untuk mengentaskan kemiskinan dan meningkatkan kesejahteraan masyarakat, maka perlu adanya pengelolaan zakat, infak dan shadaqah yang profesional dan bertangung jawab yang dilakukan masyarakat bersama pemerintah (Burhan Bungin, 1987 : 40).

Untuk terciptanya distribusi zakat yang baik, maka pemerintah berkewajiban memberikan perlindungan, pembinaan dan pelayanan kepada muzzaki, mustahiq dan pengelola zakat.

Dalam laporan penelitian ini, Peneliti sampaikan pula pengalaman salah seorang penerima bantuan kambing dari BAZNAS Karanganyar, semasa dulu istilahnya masih BAZIS Karanganyar, yakni seorang warga dari Wagah, Popongan, Karanganyar. Namanya NG (nama inisialnya Peneliti), seorang buruh dan sambilan mengelola ternak kambing di rumah yang sudah dijalaninya sekitar 2 tahun lebih. Pada saat itu Ngadiyo memperoleh bantuan kambing sejumlah 3 ekor kambing betina umur 10 bulan dan 1 ekor kambing jantan umuur 10 bulan.

Pada waktu beternak pertama kali NG hanya mempunyai 2 ekor kambing, namun dia mempunyai semangat yang gigih untuk mengembangkan ternak kambingnya, sehingga NG tergerak hatinya untuk meminta bantuan modal kambing dari BAZNAS, sebab dia sendiri merasa untuk membeli kambing tambahan dengan uang sendiri terasa berat.

Menurut Peneliti, bantuan modal berupa kambing yang diterima NG adalah salah satu bentuk bantuan modal usaha/bantuan yang bersifat produktif bagi orang tak mampu seperti yang diatur dalam UndangUndang Nomor 23 Tahun 2011 tentang Pengelolaan Zakat. 
Menurut pendapat Peneliti pula, bahwa penyaluran hasil pengumpulan zakat, infak dan shadaqah untuk modal usaha yang salah satu contohnya diwujudkan dalam bentuk ternak kambing seperti tersebut diatas sudah memenuhi amanat ketentuan yang ada pada Pasal 14 ayat (4) dan (6) Keputusan Direktur Jenderal Bimbingan Masyarakat Islam dan Urusan Haji Nomor D/291 Tahun 2000.

Untuk menangani bantuan berupa kambing secara lebih baik, BAZNAS Karanganyar membuat suatu perjanjian tertulis dengan pihak penerima bantuan dengan tujuan supaya ada ketertiban dan bisa dipantau dalam perkembangannya dilain waktu. Adanya perjanjian tertulis antara BAZNAS dengan pihak penerima bantuan seperti yang dipaparkan diatas menurut peneliti adalah sesuatu yang cukup penting. Hal ini dimaksudkan supaya ada kejelasan tentang kewajiban dan hak masing-masing pihak dan supaya bantuan itu dalam penggunaannya bisa terpantau dengan jelas. Bukankah Islam pun menyerukan agar berbagai transaksi atau perjanjian yang penting agar dibuat dalam suatu perjanjian tertulis dengan diketehui beberapa saksi. Ini adalah ketentuan Islam yang bermanfaat untuk memperjelas isi transaksi/perjanjian dan untuk mengetahui posisi, hak dan kewajiban masing-masing pihak yang terkait dalam perjanjian.

Dalam melakukan tugas sehari-hari, BAZNAS Karanganyar dibantu beberapa tenaga yang menangani teknis administrasi dan tugas-tugas di lapangan. Menurut tanggapan Peneliti, adanya tenaga-tenaga pendamping yang membantu tugas BAZNAS adalah sesuatu langkah positif pula yang diambil oleh BAZNAS. Dengan adanya tenaga-tenaga pendamping ini diharapkan tugas-tugas BAZNAS dalam menyalurkan bantuan bagi pemberdayaan ekonomi masyarakat akan lebih terarah. Tenaga-tenaga pendamping ini tentu akan selalu memonitor dan memantau penggunaan modal usaha ini agar sesuai dengan peruntukkannya. Seandainya si penerima bantuan menemui kesulitan dalam mengelola bantuan ternak kambing dari BAZNAS itu, maka para tenaga pendamping ini akan segera 
mengambil langkah-langkah pemecahannya dan berkordinasi dengan pihak BAZNAS.

Dalam pandangan Peneliti, model perjanjian bantuan BAZNAS seperti tersebut di atas patut untuk dicontoh karena menunjukkan suatu pengelolaan distribusi zakat, infak dan shadaqah yang tertib. Islam pun menyuruh agar segala sesatu urusan diselenggaakan dengan cara yang tertib dan baik termasuk pula dalam memanfaatkan zakat, infak dan shadaqah harus dilaksanakan dengan tertib pula agar pemanfaatannya bisa efisien dan tepat sasaran.

2. Kendala yang dihadapi BAZNAS Kabupaten Karanganyar dalam mengelola zakat produktif dan solusinya.

Dalam masyarakat masih saja ditemui adanya anggapan dari anggota masyarakat yang merasa kesulitan dalam mendapatkan bantuan modal usaha/bisnis. Mereka merasa bingung bagaimana cara untuk mendapatkan modal tambahan itu. Ada gagasan untuk mencari pinjaman uang di bank, tetapi mereka pun sering merasa takut terhadap segala prosedur yang diterapkan oleh bank yang dirasa cukup menyulitkan. Padahal di BAZNAS sendiri sebenarnya ada kumpulan dana-dana zakat, infak dan shadaqah yang dapat dimanfaatkan untuk kepentingan modal usaha/dagang dan kegiatan produktif lainnya misalnya untuk kepentingan peternakan.

Ketika Penelitian mewawancarai Muh. Rusdiyanto, SE, SPd.I, diperoleh keterangan bahwa untuk memperoleh bantuan kegiatan produktif dari BAZNAS sebenarnya tidak sulit. Prosedurnya cukup mudah dan tidak serumit di bank sebab BAZNAS bukan lembaga komersial yang bertujuan mencari laba sebanyak-banyaknya. BAZNAS adalah lembaga amil zakat yang bertugas untuk mendistribusikan dana zakat, infak dan shadaqah untuk kemaslahatan dan kesejahteraan masyarakat terutama kesejahteraan dan kemakmuran umat Islam.

Berbicara tentang adanya warga Muslim Karanganyar yang merasa kesulitan untuk mendapatkan bantuan modal dari BAZNAS Karanganyar, 
sebetulnya menurut Muh. Rusdiyanto, SE, SPd.I, hal itu kurang tepat sebab pada dasarnya kesulitan itu mungkin disebabkan semata-mata akibat minimnya informasi tentang peran dan tugas BAZIS dalam membantu tercapainya kesejahteraan masyarakat Muslim, bukan kesulitan prosedur dalam meminta bantuan modal usaha dari BAZNAS.

Dalam kenyataannya, sebetulnya sudah banyak masyarakat yang tak mampu mendapat bantuan modal usaha untuk kegiatan produktif dari BAZNAS. Sebagai contoh adalah Panti Asuhan Yatim Piatu Muhammadiyah pernah mendapat bantuan modal sebesar Rp. 1.500.000,00. Ada pula bantuan yang berupa ternak kambing bagi masyarakat tak mampu yang ingin mengembangkan usaha ternak. Hal ini bisa menjadi bukti bagi masyarakat secara luas yang ingin mendapat bantuan modal produktif dari BAZNAS Karanganyar.

Menurut pendapat Peneliti, berbagai bantuan modal dari BAZNAS untuk masyarakat tak mampu ini menunjukkan BAZNAS Karanganyar sudah melaksanakan amanat Undang-Undang Nomor 23 Tahun 2011 beserta peraturan-peraturan pelaksanaannya. Bantuan-bantuan itu ternyata banyak sekali membantu memberdayakan ekonomi masyarakat miskin.

Menurut Peneliti, NG - salah seorang penerima bantuan kambing dari BAZNAS Karanganyar yang Peneliti jadikan salah satu responden penelitian ini - termasuk orang yang beruntung, karena bisa mendapatkan informasi mengenai manfaat keberadaan BAZNAS di masyarakat. NG mendapatkan informasi tentang BAZNAS melaui berbagai sarana yakni melalui pengajian, melalui siaran radio RSPD Intan Pari Karanganyar dan melalui bahan bacaan di tabloid “ Karanganyar Tenteram”. Setelah mendapatkan informasi itu lalu NG berkonsultasi dulu dengan takmir masjid setempat untuk meminta rekomendasi dari takmir untuk syarat mengajukan bantuan modal ternak ke BAZNAS Karanganyar. NG kemudian berbicara lebih lanjut bahwa setelah dirinya mengajukan bantuan ternak kambing ke BAZNAS Karanganyar, lalu ada kegiatan survey dari BAZS untuk menilai kelayakan usahanya dalam mengelola 
ternak kambing itu apakah sudah memenuhi syarat atau belum. Selain survey, NG pun menyampaikan bahwa dirinya diminta menandatangani perjanjian tertulis dengan BAZNAS yang didalamnya ada ketentuanketentuan mengenai hak dan kewajiban dirinya dengan BAZIS. NG mengatakan dalam keterangannya pada Peneliti bahwa dalam beberapa kunjungan ke tempat usaha ternaknya pihak BAZNAS sering memberikan beberapa pengarahan agar bantuan kambing yang diterimanya bisa berkembang dengan baik.

Menurut pendapat Peneliti atas keterangan di atas, hal itu memang sudah sesuai bila mengacu pada Undang-Undang Nomor 23 Tahun 2011. Dalam pasal ini ditegaskan bahwa pendayagunaan hasil pengumpulan zakat berdasarkan skala prioritas kebutuhan mustahiq dan dapat dimanfaatkan untuk usaha yang produktif. Dalam penjelasan pasal ini dikatakan bahwa mustahiq itu terdiri dari delapan ashnaf yaitu fakir, miskin, amil, muallaf, raqib, gharim, sabilillah dan ibnu sabil. NG pun berpesan bila ada warga masyarakat yang ingin memperoeh bantuan kambing bisa mencontoh dirinya untuk mengajukan permohonan bantuan ke BAZNAS. Asal usahanya sunguh-sungguh dan bisa dikelola dengan baik maka usaha peternakan kambing akan mendatangkan manfaat yang cukup banyak. Dalam pandangan NG dan pengalamannya memohon bantuan ke BAZNAS, ternyata prosedur permohonan bantuan modal usaha dari BAZNAS tidak sesulit anggapan masyarakat. Bila ada warga yang merasa sulit maka hal tersebut semata-mata disebabkan belum tahu mengenai prosedur yang sebenarnya.

NG pun berpesan dan mempunyai keinginan agar dimasa mendatang sebaiknya BAZNAS memperluas macam-macam bantuan ternak yang diberikan. Sebagai contoh kalau saat ini bantuan ternak hanya berupa kambing maka dimasa mendatang ditambah lagi dengan ternak lain misalnya sapi. Selain itu diharapkan ada pula bantuan dalam bentuk lain misalnya uang, alat-alat usaha/bisnia dan sebagainya yang sesuai dengan kebutuhan-kebutuhan spesifik masyarakat. 
Pemberian bantuan BAZNAS Karanganyar terhadap masyarakat muslim tak mampu disana untuk memperbaiki kondisi kehidupan ekonomi mereka menurut Peneliti merupakan gambaran bahwa zakat, infak dan shadaqah tidak semata-mata ibadah vertikal tetapi juga berdampak horizontal. Dalam arti bahwa zakat, infak dan shadaqah itu bisa mendorong keseimbangan sosial ekonomi masyarakat.

Dengan demikian zakat, infak dan shadaqah bisa digunakan sebagai alat pemerataan ekonomi dan mencegah tertumpuknya modal sehingga tidak akan lahir monopoli. Dalam hal ini zakat, infak dan shadaqah akan memberikan manfaat ekonomi yang luar biasa sehingga bisa menggerakan sektor-sektor produktif.

Seperti yang telah Peneliti paparkan diatas bahwa yang menjadi kesulitan masyarakat dalam berhubungan dengan BAZNAS adalah dikarenakan masih minimnya informasi yang diperoleh masyarakat tentang BAZNAS. Dalam hal ini BAZNAS menempuh langkah memperbanyak penyuluhan-penyuluhan mengenai BAZNAS ke masyarakat.

Menurut Muh. Rusdiyanto, SE, Spd.I, bahwa penyuluhanpenyuluhan itu biasanya diadakan pertingkat kecamatan. Biasanya yang diundang untuk hadir adalah perwakilan-perwakilan perangkat desa, misalnya para Kepala Dusun (Kadus). Diharapkan para Kadus ini meneruskan informasi tentang BAZNAS ini pada para warganya seperti melalui pertemuan-pertemuan RT atau RW, sehingga keberadaan BAZNAS ini lebih banyak diketahui masyarakat.

Hanya saja dalam pendapat Peneliti belum ada perangkat desa atau kecamatan yang datang kepertemuan RT atau RW memberikan penyuluhan langsung pada masyarakat mengenai pengelolaan dan pendistribusian zakat, infak dan shadaqah yang dilakukan BAZNAS Karanganyar. Hal ini terutama yang Peneliti amati ditempat tinggal Peneliti. Tidak heran kiranya bila masih banyak warga masyarakat muslim 
Karanganyar yang tidak tahu menahu tentang kegiatan/tugas dan manfaat BAZNAS.

Sebenarnya hal ini dalam pandangan Peneliti menunjukkan kurang tanggapnya aparat kecamatan/desa dalam memberikan penyuluhan tentang zakat, infak dan shadaqah serta manfaat BAZNAS atau mungkin juga ada alasan lain. Dalam pandangan Peneliti yakni para perangkat desa / kecamatan merasa kurang mampu dalam menyampaikan materi tentang zakat, infak dan shadaqah itu secara langsung pada masyarakat, sehingga mereka tidak mempunyai keberanian untuk menyampaikan masalah zakat, infak, shadaqah dan materi tentang BAZNAS pada masyarakat.

Pihak BAZNAS sendiri sebenarnya mengharapkan para takmir masjid di Karanganyar ikut mensosialisasikan Undang-Undang tentang Pengelolaan Zakat, sebab takmir mesjid pasti hubungannya dengan masyarakat sekitar cukup dekat.

Pendapat dari BAZNAS tersebut menurut pendapat Peneliti memang benar bahwa kalangan mesjid sebenarnya wajib menyebarluaskan dan ikut memberi penyuluhan mengenai undang-undang itu. Hal ini dikarenakan substansi undang-undang tersebut merupakan unsur dakwah yang harus disampaikan pada jamaah untuk kepentingan kebaikan jamaah. Selain itu memang hubungan takmir masjid dengan jamaah sangat dekat karena seringnya berhubungan satu sama lain.

Menurut pendapat Peneliti pun keingian BAZNAS diatas bisa dipahami sebab kalau ada warga muslim yang miskin memerlukan bantuan dari BAZNAS diharuskan membawa rekomendasi dari masjid setempat. Hal ini disebabkan pihak BAZNAS akan lebih percaya pada pemohon bantuan yang membawa rekomendasi dari pihak masjid. Dengan demikian takmir masjid merupakan salah satu ujung tombak sosialisasi UndangUndang Nomor 23 Tahun 2011 di masyarakat agar isi undang-undang itu cepat diketahui. Menurut pendapat Peneliti pun masyarakat sendiri diharapkan berinisiatif mencari sendiri informasi mengenai BAZNAS. Untuk daerah Karanganyar misalnya bisa mencari informasi melalui Radio 
RSPD Karanganyar atau bisa juga melalui media surat kabar, tabloid dan sebagainya.

Untuk sosialisasi Undang-Undang Nomor 23 Tahun 2011 ke masyarakat tingkat kecamatan, menurut Muh. Rusdyanto, SE, SPd.I, biasanya hanya dilakukan sekali dalam setahun dengan pembagian tim BAZNAS keberbagai kecamatan. Dalam pandangan Peneliti, sosialisasi undang-undang tersebut hanya sekali per-tahun sebenarnya masih kurang sehingga akan sulit menjangkau berbagai lapisan masyarakat muslim Karanganyar yang diam diberbagai kecamatan. Seperti contoh jadwal sosialisasi yang BAZNAS Kab. Karanganyar di Wilayah desa dan kelurahan se-Kabupaten Karanganganyar serta di berbagai lokasi perusahaan yang berdiri di Karanganyar, yakni sebagai berikut (BAZNAS Kab. Karanganyar, $2015: 12-13)$ :

\begin{tabular}{|l|ll|l|l|l|l|}
\hline NO & $\begin{array}{l}\text { HARI } \\
\text { TANGGAL }\end{array}$ & $\begin{array}{l}\text { WAKTU } \\
2015\end{array}$ & KECAMATAN & LOKASI & TEAM \\
\hline 1 & $\begin{array}{l}\text { Selasa, 28 } \\
\text { April }\end{array}$ & $\begin{array}{l}10.00 \text { WIB } \\
- \text { selesai }\end{array}$ & $\begin{array}{l}\text { Tasikmadu } \\
\text { Jaten } \\
\text { Kebakkramat } \\
\text { Jumantono }\end{array}$ & $\begin{array}{l}\text { Aula Kecamatan } \\
\text { Aula Kecmatan } \\
\text { Aula IPHI } \\
\text { Aula Kecamatan }\end{array}$ & $\begin{array}{l}\text { I I } \\
\text { III } \\
\text { IV }\end{array}$ \\
\hline 2 & $\begin{array}{l}\text { Kamis, 30 April } \\
2015\end{array}$ & $\begin{array}{l}10.00 \text { WIB- } \\
\text { selesai }\end{array}$ & $\begin{array}{l}\text { Mojogedang } \\
\text { Jumapolo } \\
\text { Karangpandan }\end{array}$ & $\begin{array}{l}\text { Aula Kecamatan } \\
\text { Aula Kecamatan } \\
\text { Aula Kecamatan }\end{array}$ & I III \\
IV \\
\hline 3
\end{tabular}




\begin{tabular}{|l|l|l|l|l|l|}
\hline & & Matesih & $\begin{array}{l}\text { Balai Desa } \\
\text { Matesih }\end{array}$ & II \\
\hline 6 & $\begin{array}{l}\text { Kamis,10 } \\
\text { Desember 2015 }\end{array}$ & $\begin{array}{l}\text { 09.00 WIB- } \\
\text { selesai }\end{array}$ & ---------------- & $\begin{array}{l}\text { BKK Tasikmadu } \\
\text { BKK } \\
\text { Karanganyar }\end{array}$ & I \\
\hline 7 & $\begin{array}{l}\text { Selasa, 15 } \\
\text { Desember 2015 }\end{array}$ & $\begin{array}{l}\text { 09.00 WIB } \\
\text {-selesai }\end{array}$ & ----------- & $\begin{array}{l}\text { PT Kusuma Hadi } \\
\text { PG Tasikmadu }\end{array}$ & I II \\
\hline 8 & $\begin{array}{l}\text { Kamis, 17 } \\
\text { Desember 2015 }\end{array}$ & $\begin{array}{l}\text { 09.00 WIB- } \\
\text { selesai }\end{array}$ & ------------ & $\begin{array}{l}\text { PT Gunung } \\
\text { Subur } \\
\text { PT Air Mancur }\end{array}$ & II \\
\hline
\end{tabular}

Selain mengadakan sosialisasi Undang-Undang Tentang Pengelolaan Zakat di lingkungan masyarakat dan lingkungan perusahaan, BAZNAS Kab. Karanganyar juga secara teratur mengadakan sarasehan ulama dan umara dan pengumpulan ZIS. Beberapa contoh sarasehan yang diadakan misalnya (BAZNAS Kab. Karanganyar, 2015 : 14) :

\begin{tabular}{|c|c|c|c|}
\hline $\mathrm{NO}$ & BULAN & KEGIATAN SARASEHAN & PEROLEHAN ZIS \\
\hline 1 & Januari & $\begin{array}{l}\text { Kamis, } 29 \text { Jan } 2015 \text {, jam } 08.30 \text {, } \\
\text { di pendopo rumah dinas Bupati } \\
\text { Karanganyar } \\
\text { Ust. Seno Hadi S }\end{array}$ & 519.796 .956 \\
\hline 2 & Februari & $\begin{array}{lll}\text { Rakerda } & \text { di } & \text { BP2TOOT } \\
\text { Tawangmangu } & & \end{array}$ & 496.442740 \\
\hline 3 & Maret & $\begin{array}{l}\text { Senin, } 30 \text { Maret 2015, jam } 08.30 \\
\text { di pendopo rumah dinas Bupati } \\
\text { Karanganyar } \\
\text { Ust. H. Muha Iskandar }\end{array}$ & 509.137 .458 \\
\hline 4 & April & $\begin{array}{l}\text { Senin, } 27 \text { April 2015, jam } 8.30 \text { di } \\
\text { pendopo rumah dnas Bupati } \\
\text { Karanganyar } \\
\text { Ust. Nurhadi Warsono }\end{array}$ & 537.998 .174 \\
\hline 5 & Mei & $\begin{array}{l}\text { Kamis, } 21 \text { Mei } 2015 \text {, jam } 8.30 \\
\text { di halaman Mesjid Agung } \\
\text { Karanganyar } \\
\text { Ust KH Syarif Rahmat, SQ, M.A. }\end{array}$ & 553.444173 \\
\hline 6 & Juni & $\begin{array}{l}\text { Senin, } 27 \text { Juni 2015, jam } 8.30 \text { di } \\
\text { pendopo Rumah Dinas Bupati } \\
\text { Ust Nurhadi Warsono }\end{array}$ & 536.580 .011 \\
\hline 7 & Juli & $\begin{array}{l}\text { Senin, } 27 \text { Juli } 2015 \text {, jam } 8.30 \text { di } \\
\text { pendopo rumah dinas Bupati }\end{array}$ & 1.047 .054 .789 \\
\hline
\end{tabular}




\begin{tabular}{|c|c|c|c|}
\hline & & $\begin{array}{l}\text { Karanganyar } \\
\text { Ust Nurhadi Warsono }\end{array}$ & \\
\hline 8 & Agustus & $\begin{array}{l}\text { Senin, } 27 \text { Agustus 2015, jam } 8.30 \\
\text { di pendopo rumah dinas Bupati } \\
\text { Karanganyar } \\
\text { Ust Nurhadi W }\end{array}$ & 531.686 .982 \\
\hline 9 & September & $\begin{array}{l}\text { Senin, } 27 \text { September } 2015 \text {, jam } \\
8.30 \text { d pendopo rumah dinas } \\
\text { Bupati Karanganyar } \\
\text { Ust Nurhadi W }\end{array}$ & 528.163 .376 \\
\hline 10 & Oktober & $\begin{array}{l}\text { Senin, } 27 \text { Oktober } 2015 \text {, jam } \\
8.30 \text {, di pendopo rumah Dinas } \\
\text { Bupati Karanganyar } \\
\text { Ust Nurhadi Wasono }\end{array}$ & 527.449 .115 \\
\hline 11 & Nopember & $\begin{array}{l}\text { Senin, } 27 \text { Nopember } 2015 \text {, jam } \\
8.30 \text { di pendopo rumah dinas } \\
\text { Bupati Karanganyar }\end{array}$ & 536.163 .786 \\
\hline 12 & Desember & $\begin{array}{l}\text { Senin } 27 \text { Desember } 2015 \text {, jam } \\
8.30 \text { di pendopo rumah dinas } \\
\text { Bupati Karanganyar } \\
\text { Ust Nurhadi Warsono }\end{array}$ & \\
\hline
\end{tabular}

Dalam rangka melaksanakan Undang-Undang Nomor 23 Tahun 2011 agar terlaksana lebih baik lagi dan lebih tersosialisasi dengan lebih baik, maka BAZNAS Karanganyar mengadakan beberapa kegiatan yang menurut Peneliti memang harus demikian supaya sebuah program pemerintah itu bisa diketahui masyarakat secara lebih luas.

Kegiatan-kegiatan yang dimaksud diatas yakni (BAZNAS Kabupaten Karanganyar, $2015: 27)$ :

a. Membuka rubrik tanya jawab dan konsultasi zakat di Solopos setiap hari Jumat.

b. Menyediakan media informasi setiap bulan berupa buletin dan majalah pada akhir bulan.

c. Memasang kaligrafi kalimat toyyibah (Subhanallah, Alhamdulillah, Allahu Akbar, Astagfirullah) sepanjanng jalan Lawu-Karanganyar, mulai Colomadu sampai Tawangmangu.

d. Menyelenggarakan pelatihan kerjasama dengan BLK berupa pelatihan menjahit tahun 2015 sebanyak 16 orang. 
e. Membiayai sekolah tilawah Bintang MTQ yang diselenggarakan setiap Hari Sabtu di komples Masjid Agung Karanganyar dengan jumlah peserta 420 orang. Untuk tahun 2015 ini meluluskan 80 anak.

f. Bekrjasama dengan UNS mengadakan diklat mekanik sejumlah 40 anak tidak mampu selama 1 tahun.

Menurut Peneliti, berbagai kegiatan sosialisasi masalah Zakat, Infak dan Shadaqah (ZIS) yang dilakukan BAZNAS Kab. Karanganyar merupakan bagian dari tugas BAZNAS yang diatur dalam UndangUndang Nomor 23 Tahun 2011 dan Peraturan Pemerintah Nomor 14 Tahun 2014 sebagai peraturan pelaksanaannya. Tugas-tugas yang dimaksud dalam undang-undang di atas adalah :

Dalam Pasal 6 dikatakan bahwa BAZNAS merupakan lembaga yang berwenang melakukan tugas pengelolaan zakat secara nasional. Lalu dalam Pasal 7 dinyatakan: (1). Dalam melaksanakan tugas sebagaimana dimaksud dalam Pasal 6, BAZNAS menyelenggarakan fungsi:

a. perencanaan pengumpulan, pendistribusian, dan pendayagunaan zakat;

b. pelaksanaan pengumpulan, pendistribusian, dan pendayagunaan zakat;

c. pengendalian pengumpulan, pendistribusian, dan pendayagunaan zakat;

d. pelaporan dan pertanggungjawaban pelaksanaan pengelolaan zakat.

Bagaimana mungkin kalau BAZNAS Kab. Karanganyar bisa melaksanakan tugas di atas kalau masyarakat tidak paham akan UndangUndang Tentang Pengelolaan Zakat itu. Dalam Peraturan Pemerintah Nomor 14 Tahun 2014 diperkuat pula mengenai tugas dari BAZNAS yang hanya bisa dilakukan kalau undang-undang tersebut tersosialisasikan dengan baik.

Mengacu pada Peraturan Pemerintah di atas terlihat bahwa BAZNAS Kab. Karanganyar khususnya dan BAZNAS di Indonesia pada umumnya mempunyai fungsi sebagai mana diatur dalam Pasal 3 ayat (1) dan (2) yakni : 
1) BAZNAS merupakan lembaga yang diberi tugas mengadakan pengelolaan zakat secara nasional.

2) Dalam melaksanakan tugasnya itu, BAZNAS mempunyai fungsi:

a. Perencanaan pengumpulan, pendistribusian dan pendayagunaan zakat.

b. Pelaksanaan pengumpulan, pendistribusian dan pendayagunaan zakat.

c. Pengendalian pengumpulan, pendistribusian dan pendayagunaan zakat.

d. Pelaporan dan pertanggung jawaban pelaksanaan pengelolaan zakat.

\section{Simpulan}

1. Dalam pengelolaan zakat produktif, BAZNAS Karanganyar melaksanakan ketentuan yang ada dalam Undang-Undang Nomor 23 Tahun 2011 tentang Pengelolaan Zakat beserta peraturan pelaksanaannya. Di Kabupaten Karanganyar pendayagunaan atau pemanfaatan zakat, infak dan shadaqah diwujudkan juga dalam bentuk bantuan ternak kepada orang-orang yang tidak mampu. Untuk menciptakan ketertiban dalam pemberian bantuan itu dibuat suatu perjanjian tertulis antara BAZNAS Karanganyar dengan penerima bantuan. Selain itu ada keharusan juga bagi pemohon bantuan supaya para pemohon bantuan modal usaha membawa surat rekomendasi dari takmir masjid di tempat tinggal pemohon bantuan.

2. Kendala yang dihadapi BAZNAS Kabupaten Karanganyar dalam mengelola zakat produktif yaitu masih minimnya informasi masyarakat terhadap program-program BAZNAS. Solusi yang dilakukan diantaranya adalah BAZNAS Karanganyar sudah banyak melakukan sosialisasi tentang BAZNAS pada masyarakat terutama penyuluhan-penyuluhan kepada para camat, kades dan lurah-lurah di wilayah Karanganyar untuk diteruskan kepada masyarakat. 


\section{E. Saran}

1. BAZNAS Karanganyar hendaknya memperbanyak jenis bantuan selain ternak misalnya bantuan berupa modal usaha, alat-alat pertanian, alat-alat pertukangan dan sebagainya. Untuk bantuan ternak diusulkan lebih bervariasi seperti pemberian bantuan sapi, ayam yang berkualitas, kerbau dan sebagainya. Disamping itu, kekurangan dari sisi aspek manajemen di BAZNAS Karanganyar juga hendaknya segera dibenahi agar bisa menopang secara penuh tugas-tugas dari BAZNAS.

2. BAZNAS Karanganyar hendaknya lebih gencar lagi melakukan sosialisasi terkait peraturan tentang zakat seperti menjalin kerjasama dengan sekolahsekolah dan perguruan tinggi. Disamping itu juga mengadakan penelitian bersama dengan berbagai perguruan tinggi untuk peningkatan kualitas pengelolaan zakat pada masa yang akan datang.

\section{Daftar Pustaka:}

\section{Buku:}

Abdullah, Amin. 2000. Dinamika Islam Kultural. Bandung : Mizan.

Ali, Muhammad Daud.1988. Sistem Ekonomi Islam, Zakat, dan Wakaf. Jakarta: UIPress.

Abdul Muid, Nur Arifin dan Moh. Azis Marnawi. 2001. Sewindu BAZIS Kabupaten Karanganyar. Karanganyar : BAZIS Kabupaten Karanganyar.

BAZNAS Kabupaten Karanganyar. 2015. Laporan Kegiatan Badan Amil Zakat Nasional (BAZNAS) Kabupaten Karanganyar Tahun 2015, Rapat Kerja Daerah BAZNAS Kabupaten Karanganyar.

Bagian Proyek Peningkatan Zakat dan Wakaf. 2002. Pedoman Zakat. Jakarta: Departemen Agama Republik Indonesia.

Haq, Ziaul. 1967. Revelation and Revolution in Islam. Lahore: Vanguard Book Inayah, Ghazi. 2003. Teori Komprehensif Tentang Zakat dan Pajak. Terjemahan Zainuddin Adnan dan Nailul Falah, Yogyakarta: Tiara Wacana.

Mannan, Muhammad Abdul. 1993. Teori dan Praktek Ekonomi Islam,terjemahan Nastangin, Yogyakarta: Dana Bhakti Wakaf. 
Mangunwijaya, YB.. 1997. Gerundelan Orang Republik. Yokyakarta: Pustaka Pelajar.

Rahmat, Jalaluddin. 2000. Rekayasa Sosial, Bandung: Rosdakarya.

Shad, Abdur-Rahman. 1986. Zakat and 'Ushr. Lahore, Kazi Publication.

Shidik, Saifudin.2004. Hukum Islam Tentang Berbagai Persoalan Kontemporer. Jakarta : PT. Inti Media Cipta Nusantara.

Ulwan, Abdullah Nasih. 1985. Hukum Zakat dalam Pandangan Empat Mazhab. Jakarta: Litera Antar Nusa.

\section{Peraturan:}

Undang-Undang Nomor 23 Tahun 2011 Tentang Pengelolaan Zakat

\section{Internet:}

www. afirdauz. blogspot. co. id/2014/. Pengelolaan Zakat Produktif. 